\title{
Olhar, Explicação e Intervenção da Psicologia da Infância: Contextualização histórico- cultural-metodológica
}

\author{
Lilian Miranda Bastos Pacheco ${ }^{1}$
}

\begin{abstract}
Resumo
Este artigo destaca algumas influências culturais-econômicas-históricas que podem ser observadas ao longo da estruturação do campo de estudo da psicologia da infância. Algumas necessidades sociais, como o problema da mortalidade infantil, fracasso escolar e desajustamentos culturais devido a guerras e imigrações, demandaram a oferta de serviços e profissionalização, no intuito de oferecer orientações a respeito da criação e educação das crianças. A dispersão e diversidade de abordagens e teorias existentes hoje na psicologia da infância podem ser melhor compreendidas ao serem contextualizadas nos seus respectivos berços socioculturais.

Palavras-chaves: Psicologia da infância - influências culturais, econômicas e históricas - abordagens psicológicas; educação infantil.
\end{abstract}

Seeing, explanation and intervention in childhood psychology: historical- cultural- methodological contextualization

\begin{abstract}
This paper highlights some historical, economic and cultural influences that can be observed along the structuring of the field of Child Psychology. Some social needs, such as the problem of the infantile mortality, school failure and cultural adjustments problems due to wars and immigration, demanded the offer of services and professionalization, in order to offer guidances regarding the upbringing and the education of children. The approaches and theories existing today in Child Psychology, characterized by dispersal and diversity, can be better understood if inserted in their respective socio-cultural birthplace.

Keyword: Child Psychology - historical, economic and cultural influences - psychological approaches; guidances of children.
\end{abstract}

\section{Introdução}

À medida que se vai mergulhando nas pesquisas existentes em uma determinada área de estudo, cada vez mais forte vão surgindo algumas perguntas, como por exemplo: Por que tal questão é um problema de pesquisa? Por que tal tema é tratado por determinados constructos ou variáveis e não por outros? Por que as respostas foram encontradas daquela maneira e não de outra?

Esse tema foi tratado por Foulquié (1969) ao tentar delimitar duas questões centrais da psicologia contemporânea: primeiro, qual o objeto da psicologia. Essa questão refere-se à natureza do objeto de estudo psicológico. A segunda questão diz respeito ao como conhecer esse objeto, por qual método e teoria. Uma apresentação sistemática das diversas abordagens e sistemas psicológicos, também é proposta por Marx \& Hillix (1974). Tais compêndios deixam transparecer a diversidade de enfoques e propostas explicativas que existem no campo da psicologia da criança.

O que se pretende aqui é, em acordo com Penna (1981), deixar ver que a história de uma ciência não é uma sucessão linear e contínua de doutrinas e teorias que falam da mesma coisa e tratam dos mesmos

${ }^{1}$ Endereço para correspondência:

E-mail:lmbpacheco@hotmail.com problemas. Mas, pelo contrário, apontar alguns aspectos que revelam atitudes de pensamento e domínios da pesquisa que sofrem alterações com o tempo, espaço e cultura.

A forma de tratar e delimitar os problemas de pesquisa são marcados pela abordagem teórica e metodológica que o autor utiliza. Talvez um enfoque histórico do campo de estudo da Psicologia Infantil seja uma alternativa para que se possa compreender essas influências. Nesse sentido, tentar-se-á reunir aqui algumas informações, apresentadas por Sears (1975) e Grusec \& Lytton (1988), que possam mostrar como metodologias e teorias que tem se desenvolvido em diferentes culturas, economias e climas históricospolíticos tem um impacto na maneira em que as perguntas são formuladas e os dados interpretados.

É importante notar que as teorias não se desenvolvem independentemente das crenças, atitudes e valores pessoais de uma época, das experiências cotidianas das pessoas. Em alguma extensão as teorias refletem o que seus autores sentem a respeito de como a realidade deveria ser. Eles são parte inseparáveis de um amplo sistema cultural/histórico e não podem ser considerados fora desse sistema.

Esse enfoque justifica-se na medida em que ajuda a perceber como e porque as idéias sobre a criança e a infância têm sido influenciadas pelas crenças populares 
prevalecentes e atitudes do tempo em que foram formuladas. Tal abordagem ajuda a ver como as concepções atuais são condicionadas pelo clima social contemporâneo.

\section{Perspectiva Histórica do Conceito de Criança e Infância}

Tanto o objeto de estudo da psicologia da infância, quanto suas formulações teóricas vão ganhando contornos de acordo com a cultura contemporânea às suas formulações. Com Ariès (1981) e Penna (1981) pode-se acompanhar a mudança na concepção de criança e infância que se deu com o Iluminismo. Até a Idade Média a criança não possuía uma natureza diferenciada. Após os sete anos ela era inserida na sociedade, participando do trabalho, festas, brincadeiras, rituais, etc., tal qual um adulto.

Foi no século XVI e XVII que Reformadores e Moralistas propagaram a noção de que as crianças são inocentes e corruptíveis e devem ser segregadas da sociedade e treinadas antes de poderem reunir-se ao mundo dos adultos. O que antes era aprendido na atividade diária, na experiência da vida, então passou a ser ensinado em um espaço especial - a escola.

As crianças foram sentimentalizadas, é a época da inocência juvenil. Quando pessoas jovens são tratadas como qualitativamente diferentes das mais velhas, quando são consideradas inocentes em lugar de marginalizadas, elas tendem a ter as características que lhes são atribuídas. Embora isso não queira dizer que as teorias modernas a respeito da criança sejam ficções, apenas destaca as condições históricas da infância. O que também não quer dizer que não existam algumas características do ser humano que se mantenham perenes, apesar das alterações nas condições socioculturais.

Início do Século XIX: Influências bistóricas e filosóficas na Psicologia da Infância

A grosso modo pode-se identificar duas tendências histórico-político-cultural que influenciaram a Psicologia a partir da virada para o século XIX (1890-1920). De certa forma o Oceano Atlântico é o divisor de águas, já que cada uma dessas tendências bem se expressaram o racionalismo na Europa Continental e o empirismo na América do Norte, que distingue entre a psicologia do inconsciente ou psicologia da subjetividade e a psicologia sem consciência ("caixa-preta") ou psicologia da objetividade, respectivamente. Cabe salientar que a psicologia da objetividade esteve sob a influência da filosofia e vertente metodológica do Empirismo inglês (Foulquié, 1969). Pode-se depreender, portanto que cada contexto geográfico é habitado por uma sociedade um tanto quanto específica, banhada por filosofias, culturas e condições de vida bastante diferentes. O ser humano imerso nesses dois territórios histórico-geográfico interpelou a Psicologia de formas bem distintas (Sears, 1975; Grusec \& Lytton, 1988).

$\mathrm{Na}$ psicologia americana refletem-se aspectos como conquista, desenvolvimento, oportunidade, geralmente direcionados para ajudar e mudar as pessoas, tão próprios a uma história de desbravamento e colonização. O conceito proposto por Locke, do ser humano como uma tabula rasa (enfatizando o acréscimo de experiências ao espaço em branco) é uma noção básica a esta tradição do pensamento, que se ajustará ao enfoque que busca identificar as mudanças possíveis ao longo do desenvolvimento e controle do comportamento humano (Penna, 1981).

Do outro lado do Oceano, a Psicologia continental européia estava envolvida com a compreensão do funcionamento humano. Sob a influência filosófica de Leibnitz, concebiam a mente como tendo uma atividade potencial, que deveria ser descrita e compreendida (Penna, 1981).

Autores como Riegel (1972) e Buss (1975) estabelecem algumas relações deixando antever como as ideologias político e econômicas na Europa Continental, Inglaterra e América do Norte dão origem a distintos enfoques psicológicos. Teóricos como Piaget (1983) e Freud (Marx \& Hillix, 1974) são percebidos como estando inseridos numa sociedade européia, em que havia uma estrutura de classes altamente definida por centenas de anos. Nobres e clérigos que possuíam poder e prestígio a custa da exploração de camponeses e trabalhadores. Pode-se observar coexistência em sociedades com estratos sociais hierarquizados e teorias mais conservadoras.

Abordagens filosóficas, como as de Leibnitz e Hegel (Penna, 1981), justificaram a existência de ordens sociais a fim de prevenir transtornos políticos. As idéias que sustentavam a preservação do status social, terminou por fortalecer a consciência e sensibilidade de diferenças grupais, indicando determinado grupo como padrão. Tal influência marcou as teorias de desenvolvimento infantil, tanto de Piaget como de Freud. Ambas conceberam o processo de desenvolvimento através de estágios espontâneos, concentrando-se em descrevê-los e afirmar ou a impossibilidade ou a falseabilidade de mecanismos de aceleração do desenvolvimento humano, tanto em termos de personalidade como no que se referem às funções cognitivas da criança.

Já na América do Norte as fontes das diferenças foram atribuídas à presença ou ausência de oportunidades ambientais. As pessoas com sucesso foram aquelas bem sucedidas em suas atividades e as pessoas que não obtinham êxito foram consideradas subpadrões. Havia na América um desejo de acelerar o 
processo de desenvolvimento ao máximo possível.

\section{Início do Século XIX: Necessidades sociais}

A teoria e a ciência psicológica da infância vai se organizando imersa em contextos políticos, geográficos e culturais, como vem sendo abordado, em resposta a demandas sociais. O que se observou é que o interesse pelo estudo do desenvolvimento da criança formou-se valendo-se da necessidade de melhorar sua saúde, criação e educação. Muitas mulheres tinham perdido seus filhos em razão da falta de conhecimento sobre a saúde e desenvolvimento da infância. $\mathrm{Na}$ segunda década do século XIX profissionais da Medicina e Educação iniciaram relevantes pesquisas para melhorar suas habilidades. As pesquisas deveriam ser direcionadas a todos os problemas de desenvolvimento e bem-estar das crianças. O objetivo era o de construir um corpo de conhecimentos factual sólido, que deveria beneficiar as crianças e habilitar pais e especialistas infantis para um trabalho mais efetivo na criação e educação de seus filhos. Contudo, suas principais influências nas ciências do futuro pode ser detectada na rápida expansão de serviços de atendimento às crianças nas escolas, hospitais, clínicas e agências sociais.

\section{Início do Século XX: Influências históricas e metodológicas}

As condições históricas e as demandas sociais vai contribuindo para a institucionalização da psicologia da infância. Em 1867, o Congresso Norte Americano autorizou o estabelecimento do Departamento de Educação, que viria a se tornar o U. S. Office of Education em 1929. Escolas Normais e institutos para treinamento de profissionais criaram departamentos ou escolas de Educação. Gradualmente a comunidade foi se especializando no cuidado e educação das crianças. Essa expansão continuou após a Primeira Guerra Mundial, quando cientistas de várias disciplinas das ciências puras começaram a juntar-se aos pesquisadores de várias profissões orientadas à criança, dando forma ao que hoje se conhece como campo científico que estuda o desenvolvimento da infância - Desenvolvimento da Criança.

No início do século XX as pesquisas estavam orientadas para três questões básicas. A primeira interrogava sobre como ensinar, o que, a quem. Nessa época destacaram-se os estudos de Thorndike e Woodworth (Marx \& Hillix, 1974) a respeito da transferência de aprendizagem, que enfatiza muito mais as características dos alunos do que do professor. A segunda questão tratava do currículo, que se caracterizou por uma educação liberal, elitista ou pelo treinamento vocacional. A terceira questão buscou saber quem era capaz de aprender. Esta foi especialmente tratada pela Psicologia das Diferenças Individuais. Em 1904 a escola parisiense adotou o instrumento de Binet \& Simon (Foulquié, 1969) como um método de seleção daquelas crianças que precisavam de um tipo especial de ensino, devendo ser excluídas do sistema regular. $\mathrm{O}$ teste de inteligência foi o resultado desses esforços e marcou a história da ciência psicológica. O indivíduo é de certa forma responsabilizado pelas diferenças que são sociais também.

O método experimental da fisiologia, o estudo de caso da medicina, psiquiatria, psicofísica e psicologia introspectiva não requeriam o uso de precisão da teoria da probabilidade para avaliar a significância do dado (Penna, 1981; Piaget, 1983). Em muitos casos o fenômeno estudado era suficientemente exato em suas manifestações e as diferenças entre as condições eram suficientemente grandes. Entretanto, quando Galton começou a interessar-se pelas características genéticas humanas, descobriu que existia uma variabilidade entre os indivíduos em termos de traços ou comportamentos, notando que, às vezes, a probabilidade de ocorrência de uma determinada característica apresentava significativa diferença para cada grupo (Anastasi, 1972).

Ao final da década de 1920, com os dados coletados pelos estudos normativos, a complexidade das relações causais que se estabelecem entre as características do comportamento, ou seja, sua multiplicidade pôde começar a ser desemaranhada. Ao término da Primeira Guerra Mundial, o método estatístico foi imediatamente aplicado a todas as ciências sociais e comportamentais.

\section{Inicio do Século XX: Demandas sociais como problema de pesquisa}

O grande influxo das famílias do sul e oeste europeu, na década de 1890, encheu as escolas com crianças que não somente sofreram desvantagens de linguagem, como também muitos problemas emocionais, por causa da imigração e seus conseqüentes choques culturais. O surgimento dessas dificuldades levou alguns clínicos a se dedicarem ao estudo de distúrbios das crianças e aplicação de procedimentos para tratamento. A experiência clínica e a medicina produziram uma série de observações e informações que contribuíram para a formulação de teorias de desenvolvimento da personalidade.

$\mathrm{O}$ atraso ou fracasso escolar, quando situado em seu contexto histórico revela suas implicações sociais. Todos os estudos acerca da inteligência e instrumentos de mensuração do QI, o grande interesse pelas habilidades mentais superiores foram determinados por necessidades sociais. Era mister atender às demandas de algumas instituições, como por exemplo a escola.

$\mathrm{O}$ avanço tecnológico, correspondente à era contemporânea, encurtou as distâncias, facilitando os deslocamentos, as comunicações e cobrou o desenvolvimento de habilidades para manusear as novas 
tecnologias e instrumentos, impondo maiores exigências ao ser humano e à sua capacidade de aprender e se adaptar às novas condições. Pode-se dizer que o problema da mortalidade infantil já fora solucionado, a não ser quando associado a condições de pobreza. Todavia, o problema da humanidade, atualmente, talvez seja a garantia de sua sobrevivência psicológica. Recursos materiais têm sido disponibilizados, mas o conhecimento dos recursos humanos que garantam a sua adaptação às necessidades modernas precisa ser sistematizado.

\section{Psicologia da Infância: Tendências teórico-metodológicas}

Historicamente, a Ciência da Psicologia da Infância foi influenciada, desde sua origem, pela Medicina, Estatística, estudos normativos, Psicanálise, mensuração da inteligência, Teoria do Comportamento, dentre outras. Os estudos foram direcionados para identificar aspectos normais e patológicos do desenvolvimento. Nutrição e desenvolvimento físico foram focos centrais após a Primeira Guerra Mundial.

A confluência de fontes científicas e sociais levou ao desenvolvimento paralelo de duas abordagens separadas na ciência do desenvolvimento da criança. Uma foi a abordagem clínica e a outra foi uma disciplina mais formalmente estruturada, orientada à experimentação e mensuração, genericamente denominada de abordagem experimental.

A primeira abordagem foi organizada em torno de estudos de casos clínicos e criou o campo e teoria do desenvolvimento da personalidade. A segunda foi organizada em torno de laboratórios e estudos de campo cuidadosamente controlados. Dos esforços de ambas pôde-se acumular conhecimentos, melhorar os métodos e construir teorias apropriadas aos problemas específicos do novo campo de estudo que se estruturava - a Psicologia da Infância.

Em 1896, Lightner Witmer tinha aberto a primeira clínica psicológica na University of Pennsylvania, com ênfase em problemas escolares. Naquela época o campo de estudo do desenvolvimento infantil já estava marcado por uma das características centrais, que é a multidisciplinaridade. A medicina científica, a psicologia clínica, o serviço social, o diagnóstico educacional, ao longo de três décadas desde 1890, foram progressivamente contribuindo para a descoberta da diversidade de causas do desajustamento escolar, mais do que para a formação de um único campo profissional bem delimitado. Isso provocou o surgimento de uma diversidade de especialistas na escola, como consultores sociais com especialidades diversas, psiquiatras, pediatras, além do quadro de psicólogos.

A orientação infantil do tipo clínico foi se desenvolvendo por equipes interdisciplinares de psiquiatras, psicólogos e assistentes sociais. Cada um dos quais examinava a criança encaminhada com suas técnicas de diagnóstico próprias. Quando o corpo de informações necessários era assegurado, o caso deveria ser discutido em uma reunião de equipe em busca de um consenso em torno do diagnóstico e procedimento terapêutico recomendável.

Apesar das experiências clínicas referirem-se a crianças problemas, logo tornou-se evidente que os mesmos princípios de desenvolvimento observados nos casos clínicos poderiam ser aplicados às crianças normais. A teoria da personalidade de Freud, com seus conceitos de desenvolvimento psicossexual, motivação inconsciente e mecanismos de defesa, influenciaram de forma central a teoria do desenvolvimento. Foi a orientação clínica que começou a revelar a importância das variáveis motivacionais e de personalidade para a realização escolar. Por outro lado, a influência de assistentes sociais levou a uma rica compreensão do papel de elementos sociais, especialmente aqueles referentes à tensão intrafamiliar no desenvolvimento emocional das crianças.

Durante a década de 1920, no pós-guerra, a teoria do desenvolvimento infantil foi aplicada ao problema do cuidado da criança normal. Temas como personalidade, ajustamento social e problemas do cotidiano das crianças levaram à conversão de princípios sociais e psicológicos para o enfoque de contextos familiares e grupo de pares. Foram essas abordagens, junto a materiais de casos clínicos, que contribuíram para a formulação da teoria do desenvolvimento da personalidade. A partir da década de 20 a Antropologia fez algumas contribuições à psicologia da infância em termos do estudo dos costumes, estrutura social e mais especificamente do contexto familiar, assim como em termos metodológicos, formalizando o método transcultural de pesquisa e estudos etnográficos.

Em 1924 as orientações clínicas da criança fundiramse em um grupo profissional, a American Orthopsychiatric Association. Em 1930 começou a publicação de periódicos especializados, que forneceu um meio para a comunicação de dados e discussões em simpósios, concernentes aos problemas profissionais e teóricos da orientação infantil e desenvolvimento da personalidade. O grupo citado editou o American Journal of Orthopsychiatry. Como se poderia esperar, este grupo terminou tratando de problemas de desvio de comportamento.

Por sua vez, a tendência de abordagem experimental fundou a Society for Research in Child Development, em 1934, também na América do Norte, iniciando no ano seguinte a publicação de três jornais associados: Child Development, Child Development Abstract e o SRCD Monographs.

A quantidade de informações factuais e metodologias de pesquisas acumuladas nas duas décadas entre as 
Guerras Mundiais foi enorme, tanto no campo da Psicologia como da Medicina. Nas décadas de 30 e 40, quase a metade dos artigos publicados no Child Development inseriam-se no campo da padronização do desenvolvimento. Várias funções mentais como memória, percepção, inteligência, capacidades sensoriais, emoção e um amplo espectro de problemas imprecisamente chamados de personalidade e motivação foram estudados. Dados normativos foram obtidos em muitas dessas áreas em todas as idades desde o nascimento até a adolescência.

\section{O Desafio Histórico da Transdisciplinaridade}

Em virtude da tendência, encontrada no campo da psicologia da infância, de integrar contribuições de diferentes áreas do conhecimento surgiu referência ao valor da perspectiva interdisciplinar. No campo de estudo do desenvolvimento da criança freqüentemente observam-se referências ao valor da pesquisa interdisciplinar. Para o pesquisador, por um lado, afogado nas minúcias do delineamento do seu problema de estudo e, por outro lado, tentando desemaranhar os infinitos tipos de variáveis do comportamento humano, o mérito da interdisciplinaridade pode representar um desafio perigoso.

Segundo Grusec \& Lytton (1988), essa meta não pode ser datada em estudos recentes. Pelo contrário, já em 1941, na Universidade de Chicago, houve uma corajosa tentativa de implantar um doutorado transdisciplinar em Desenvolvimento Humano, por meio da coordenação dos conhecimentos acumulados. Contudo, logo descobriu-se que os candidatos a doutorado foram necessariamente especializando-se no conhecimento e técnica de disciplinas específicas.

Uma tal integração dos conhecimentos parecia possível em razão de dois fatores principais. No âmbito da prática é possível aos especialistas integrarem o que os pesquisadores têm fracionado. $\mathrm{O}$ outro aspecto que dá a idéia de integração refere-se aos novos problemas e inquietações de alguns especialistas que trabalham nas margens entre duas ou mais disciplinas de pesquisa.

A transdiscilinaridade continua a ser um desafio até os dias de hoje para especialistas, pesquisadores e professores. Aliás, é meta central da proposta de ensino lançada pelos Novos Parâmetros Curriculares. Todavia, as condições para atingir a integração dos conhecimentos não são mais favoráveis do que antes. Talvez a diversidade de constructos, concepções teóricas e metodológicas sejam a característica mais marcante da dispersão imanente à produção de conhecimento. Como exemplo, a própria questão da integração do conhecimento está mergulhada num emaranhado de conceitos como multidisciplinaridade, interdisciplina- ridade e transdisciplinaridade.

Após a Segunda Guerra Mundial houve uma vigorosa expansão do campo de desenvolvimento infantil nos departamentos de Psicologia e a Psicologia Clínica foi incorporada nas academias. Nos anos 40 e 50, a Psicanálise exerceu enorme influência, ao lado do Behaviorismo. No entanto, a influência entre a Psicologia Experimental e a Psicanálise era unidirecional. Os achados sobre processos intelectuais, percepção, aprendizagem, desenvolvimento da linguagem, permaneceram ignorados até metade do século XIX. Esse foi mais um elemento que insuflou a divisão entre os estudantes de laboratório e clínicos da Psicologia da Criança.

Por outro lado, nos Estados Unidos, nos anos 30 e 40, muitos terapeutas de orientação clínica foram hábeis na contextualização do desenvolvimento humano, produzindo um conhecimento mais eclético que contemplava tanto os achados empíricos da clínica como as pesquisas de laboratório e não somente da Psicologia como também de outras ciências sociais. Nos anos 60 assistiu-se a uma diminuição da influência psicoanalítica, em parte resultante da mudança de interesse dos aspectos motivacionais ou de personalidade para os aspectos cognitivos.

Apesar disso, pode-se notar que muitos dos problemas considerados pelo método analítico e suas variáveis, tiveram um papel central na formação do campo de desenvolvimento da personalidade. Por exemplo, relações objetais, apego, dependência, agressão, rivalidade entre irmãos, desenvolvimento do papel de gênero, influências da criação da criança, motivação para a realização, todas essas são áreas de pesquisa da Psicologia Infantil, descobertas inicialmente como variáveis essenciais à teoria psicanalítica.

Esses esforços, todavia, não conduziram à unificação científica. Pelo contrário, outros especialistas no desenvolvimento terminaram por construir diferentes tipos de teorias que pudessem incorporar várias qualidades comportamentais. A década de 70 assistiu a uma substancial infusão de eventos e teorias que derivaram menos da ciência multidisciplinar do desenvolvimento do que de campos ou tendências específicas da Psicologia.

O status que a transdisciplinaridade têm obtido revela um percurso típico da produção de conhecimento científico. Tradicionalmente as várias ciências consideram-se como disciplinas separadas e distintas. Cada qual definida e delimitada para destacar as suas características específicas. Entretanto, os campos se expandiram e passaram a sobrepor-se, em certas áreas, com os campos adjacentes. Desenvolveram-se, então, os campos de transição ou interdisciplinares.

A Psicologia tem uma especificidade nesse processo. Seu objeto de estudo apresenta-se sob dois aspectos 
(Foulquié, 1969; Marx \& Hillix, 1974): um alcançado pela introspecção, que constitui os elementos da vida interior (sensações, imagens, memória, sentimentos, pensamentos, volição, etc.); o outro, são as expressões do psiquismo (atitudes, gestos, linguagem e todos os fenômenos orgânicos concomitantes à operação mental). Em decorrência, gerou-se um dualismo metodológico, já que contempla tanto fatos internos, quanto externos.

As discussões e críticas metodológicas levaram à restrição da legitimidade do método introspectivo. Este tornou-se um dos elementos geradores do caráter fragmentário do dado psicológico, tudo o que escapava à observação externa foi negligenciado. Os estudos fisiológicos buscaram suprir a inacessibilidade aos eventos internos, respaldado pela concepção de que a todo fato psíquico corresponde uma alteração material na química cerebral. Assim, coloca-se como uma solução na medida em que pode ser avaliada por métodos fisiológicos.

Telford \& Sawrey (1973) salientam que a natureza dual do objeto de estudo psicológico fundamenta-se na própria natureza da Psicologia, que se origina em um ponto de interseção entre a Biologia e as Ciências Sociais, através de um processo de distinção da Filosofia, podendo ser considerada como uma ciência biossocial. Contudo, a dispersão ampliou-se à medida em que as áreas de estudo foram se desenvolvendo no interior do campo de estudo psicológico.

Poder-se-ia dizer que há uma interdisciplinaridade interna ao próprio campo da psicologia. Por exemplo, a Psicologia enfoca o fato do ser humano ser um organismo biológico e ao mesmo tempo um ser social. Certos estudos ou áreas de concentração buscam informações no organismo, que possam ajudar a compreender as atividades humanas. Uma delas, a Psicologia Fisiológica, investiga as relações entre o sistema límbico e as emoções, o sistema nervoso autônomo e a impulsividade ou reatividade do ser humano, etc. Já a Psicologia Social destaca o fato de que, se o ser humano desenvolve-se num meio social, é impossível escapar aos efeitos da sociedade. Por conseguinte, o psicólogo social emprega métodos e técnicas para analisar as influências sociais que se fazem sentir no indivíduo, analisando a força de instituições ou agências sociais como família, escola, religião, Estado, relação com os pares ou com autoridades, etc.

Cada área de concentração dessas tem suas teorias e constructos, que às vezes utilizam os mesmos termos mas com sentidos diferentes, como também se pode encontrar termos diferentes com significados semelhantes. Essa dispersão e a necessidade de intercâmbios levaram a algumas revisões e sínteses. Isto que pode ser visto, por exemplo, no campo da Psicologia Social experimental. Ela se desenvolveu explosivamente durante as décadas de 1950 e 1970. O trabalho pioneiro de Kurt Lewin (Garcia-Roza, 1972) e seus seguidores, que submeteram vários aspectos do comportamento social ao estudo experimental em laboratório, forneceu uma grande quantidade de dados sobre as relações sociais. Tais informações forçaram a revisão das teorias, levandoas a contemplarem um grupo mais vasto de variáveis. Teorias mais compreensivas do comportamento social têm sido propostas. No entanto, a dispersão nessa área de estudos psicológicos pode ser observada na diversidade de constructos que são utilizados nas pesquisas que tratam da dimensão social do ser humano.

Em suma, o que se pode perceber com base nessa abordagem é que a história de uma ciência é uma diversidade, com vários fatos interrompidos e às vezes recuperados períodos depois. Alguns velhos fatos ou constructos, que foram uma vez irrelevantes, tornam-se centrais para a história quando o conteúdo e métodos da ciência mudam. Todavia, isso não parece ocorrer de forma aleatória e sim de forma coerente com a sociedade que produz a ciência psicológica e, também, com a clientela a qual se destina.

A partir da década de 70 o campo da Psicologia da Infância encontrava-se dividido entre diversas tendências principais: a Psicometria e os estudos estatísticos de normatização e correlação; a Psicanálise com sua teoria do inconsciente; a Psicologia Social com a teoria da aprendizagem social e seus estudos sobre agressão, dependência e moralidade ou ainda a teoria da aprendizagem social cognitiva, que reconheceu a importância de constructos mentais, tal como estratégias de enfrentamento, expectativas, incentivos e competências; a Psicologia Cognitiva, com a abordagem sociohistórica, os estudos do processamento de informação, atenção, memória e atribuição de causalidade; estudos culturalistas antropológicos; estudos etológicos, sociobiológicos e psicobiológicos preocupados com a relação entre comportamento e evolução, por exemplo, a Teoria Psicogenética que explica o desenvolvimento através da teoria da equilibração (Piaget, 1976).

Com tamanha diversidade de abordagens os dias de rigorosa aderência a uma posição teórica ou a pontos de vista opostos que competem entre si foi caindo em desuso. Os pesquisadores tinham-se tornado menos rígidos nesse sentido. $\mathrm{O}$ objetivo não era obter um conhecimento final com uma teoria que abrangesse tudo. A Etologia com a abordagem da aprendizagem social é um exemplo dessa nova postura de integrar conhecimentos tanto do Behaviorismo quanto da Psicanálise. No entanto, autores como Penna (1997) identificam uma impossibilidade de unificação no pensamento psicológico, por causa da diversidade de 
matrizes epistemológicas que coexistem em seu bolo.

As estruturas teóricas, quando compreendidas de forma contextualizada permitem perceber que, tal como os organismos vivos, também a produção do conhecimento sofre interferências das atitudes e valores da cultura contemporânea em sua produção. Muitas vezes o objetivo dos estudos e pesquisas têm sido modificados pelo contexto histórico da época, ganhando outros rumos ao longo do trabalho. A compreensão do comportamento humano, entretanto, pode transcender limites históricos, na medida em que as mudanças na biologia humana são muito mais lentas do que as circunstâncias culturais, ou seja, apesar do ser humano ser capaz de aprendizagem, ele não é totalmente flexível ou maleável. Algumas características que o constituem persistem no tempo, o que possibilita falar em um sujeito até certo ponto universal. O desafio para os estudiosos é ver como as experiências biológicas e culturais estão entrelaçadas.

\section{Complexidade das V ariáveis que Incidem sobre o Comportamento}

O comportamento das crianças não pode ser entendido adequadamente, a menos que se considere que ele afeta as reações dos outros e está inserido num amplo contexto social que vai além da situação imediata. Está inserido em sistemas sociais sujeito a uma variedade de influências - pais, grupos de pares, parentes, professores, escola, mídia, clubes, etc. - que interagem e modificam o impacto um do outro. Por exemplo, uma criança que tem uma relação estável e de confiança com seus pais pode não ser afetada por atos anti-sociais de um de seus pares.

A importância do complexo ambiente no qual indivíduos estão inseridos, foi enfatizada pela teoria de campo de Kurt Lewin (In Garcia-Roza, 1972). Um dos seus discípulos, Roger Barker (In Grusec \& Lytton, 1988, 39), propôs a "psicologia ecológica", a fim de estudar a acomodação mútua entre o desenvolvimento do organismo e suas alterações ambientais. Ele defendia que alguma ciência do comportamento deveria estar consciente de uma extensão mais ampla de eventos que têm impacto no indivíduo. Pretendeu, assim, descrever detalhadamente o ambiente da criança ao longo de dias inteiros.

O desafio de relacionar a totalidade dos eventos observados no ambiente da criança e os resultados psicológicos permaneceu um sério problema. A opção metodológica foi concentrar-se em poucas variáveis no tempo. Metodologias modernas e avanços estatísticos têm tentado contribuir para a operacionalização dos princípios da Psicologia Ecológica.

Apesar de tal proposta contemplar um número de variáveis mais ampla, do que quando se considera apenas o indivíduo independente do meio ambiente, o espectro ainda é necessariamente limitado, pois o ambiente da criança não é afetado apenas por eventos que ocorrem no seu ambiente circundante com seus eventos temporais e físicos imediatos. Pelo contrário, envolve o mundo social mais amplo. Quatro dimensões a princípio poderiam ser citadas, o contexto imediato (por exemplo, a sala de aula), outro contexto principal no qual a criança passa boa parte do seu tempo (por exemplo, seu lar), outras instituições da sociedade (por exemplo, o mundo do trabalho, facilidades de comunicação, etc.), a ideologia da sociedade (por exemplo, regras formais e informais de bons costumes, etc.).

As teorias e metodologias científicas não deveriam ser utilizadas de forma ingênua, pois não são neutras, mas estão inseridas em um contexto histórico-social. É preciso, portanto, conhecer não só as proposições de cada abordagem, mas seu objeto de estudo e contexto metodológico em que se insere, para que se possa melhor conhecer suas limitações e possibilidades. Hoje há uma diversidade de abordagens iniciadas. Cobra-se, ao profissional ou pesquisador, um posicionamento crítico em relação às crenças e valores contemporâneos para que não se caia em modismos ou falsas soluções.

\section{Referências Bibliográficas}

Anastasi, Anne. (1972). Psicologia Diferencial. $5^{\mathrm{a}}$ reimpressão. São Paulo: EPU, 782p.

Ariès, Philips. (1981). História Social da Criança e da Família. Rio de Janeiro: Zahar.

Buss, A. K. (1975). The emerging field of the sociology of psychological knowledge. American Psychologist, 30, 9881002.

Foulquié, Paul. (1969). A Psicologia contemporânea, 3a ed., São Paulo: Editora Nacional, 393p.

Garcia-Roza, Luiz Alfredo. (1972). Psicologia Estrutural em Kurt Lewin. Rio de Janeiro: Editora Vozes, 244p.

Grusec, Joan E. \& Lytton, Hugh. (1988). Social Development: History, Theory, and Research. New York, Springer-Verlag New York Inc.

Marx, Melvin H. \& Hillix, William A. (1974). Sistemas e Teorias em Psicologia. 2.ed. São Paulo: Cultrix, 755p.

Penna, Antonio G. (1981). História das Idéias Psicológicas. Rio de Janeiro: Zahar Editores, 151p.

Penna, Antonio G. (1997). Repensando a Psicologia. Rio de Janeiro: Imago Ed., 300p.

Piaget, Jean. (1976). A Equilibração das Estruturas Cogniti-vas: problema central do desenvolvimento. Rio de Janeiro: Zahar Editores.

Piaget, Jean. (1983). A epistemologia genética / Sabedoria e ilusões da filosofia / Problemas de psicologia genética. 2.ed - São Paulo: Abril Cultural, Os Pensadores.

Riegel, K. F. (1972). Influence of economic and political ideologies on the development of developmental psychology. Psychological Bulletin, 78, 129-141. 
Sears, Robert R. (1975). Your Ancients Revisited: A History of Child Development. In Hetherington, E. M. (Ed.). Review of Child Development Research. Chicago and London: University of Chicago Press, v.5, 1-75.

Shaw, Marvin E. \& Castango, Philip. (1970). Theories of Social Psychology. New York: McGraw-Hill Book Company, $414 \mathrm{p}$.
Telford, Charles W. \& Sawrey, James M. (1973). Psicologia: uma introdução aos princípios fundamentais do comportamento. 4.ed., São Paulo: Cultrix, 530 p.

Recebido em 11/04/2001

Revisado em 07/06/2001

Aceito em 21/06/2001

Sobre a autora:

Lílian Miranda Bastos Pacheco é Graduada em Psicologia pela Universidade Federal da Bahia (FFCH-UFBA) em 1990. Professora Assistente do Departamento de Educação da Universidade Estadual de Feira de Santana (EDU-UEFS) desde 1993. Mestre pela Faculdade de Educação da Universidade Estadual de Campinas (FEUNICAMP), junto ao Grupo de Estudos e Pesquisa em Psicopedagogia (GEPESP) em 1998. 